\title{
LA PROTECCIÓN AMBIENTAL EN EL DERECHO CONSUETUDINARIO INTERNACIONAL
}

\author{
Jorge E. VIÑUALES*
}

\begin{abstract}
SUMARIO: 1 . INTRODUCCIÓN.-2. SÍNTESIS DE LA MATRIZ CONSUETUDINARIA IDENTIFICADA POR LA JURISPRUDENCIA.-3. DILIGENCIA DEBIDA EN EL MARCO DEL PRINCIPIO DE PREVENCIÓN.-4. OBLIGACIÓN DE COOPERACIÓN DE BUENA FE.5. EXIGENCIA DE UNA EVALUACIÓN DE IMPACTO AMBIENTAL.—6. DESAFÍOS ACTUALES.
\end{abstract}

\section{INTRODUCCIÓN}

En un artículo publicado a finales del año $2008^{1}$, concluimos que la importancia de la protección del medio ambiente había sido claramente reconocida por la jurisprudencia internacional. Sin embargo, dicho reconocimiento no había alcanzado aún un grado suficiente de detalle. En particular, en lo que llamamos la «tercera fase» de la jurisprudencia ambiental, se identificaron los avances que podían esperarse de dicha jurisprudencia en los años siguientes, entre los cuales la determinación del Derecho consuetudinario en esta materia y el reconocimiento de derechos humanos de naturaleza o de contenido ambiental ${ }^{2}$.

En poco menos de diez años, la jurisprudencia ha brindado afortunadamente gran parte de los desarrollos que podían preverse en el $2008^{3}$.

\footnotetext{
* Catedrático de Derecho y Política Ambiental, Universidad de Cambridge, Reino Unido. El presente estudio fue realizado en el marco de una estadía como profesor visitante en la Facultad de Derecho de la Universidad Autónoma de Madrid, a inicios de 2016. Quisiera agradecerle a los colegas y amigos de dicha Facultad, y en particular al Profesor Carlos Espósito, Catedrático de Derecho Internacional Público, por la amable invitación y la generosa hospitalidad. Contacto: jev32@cam.ac.uk.

1 Viñuales, J. E., "The Contribution of the International Court of Justice to the Development of International Environmental Law», Fordham International Law Journal, vol. 32, 2008, pp. 232-258.

2 Ibid., pp. 257-258.

3 Véanse además los excelentes estudios sobre el desarrollo jurisprudencial de esta rama de JUSTE RuIz, J., «The International Court of Justice and International Environmental Law», en International Courts and the Development of International Law: Essays in Honour of Tullio Treves, La Haya, Asser Press, 2013, pp. 383-401; FitzMauricE, M., «The International Court of Justice and International En-
} 
El presente estudio tiene por objeto analizar uno de los dos componentes principales de estos desarrollos, a saber el estado actual del Derecho consuetudinario en materia de protección ambiental, a la luz de su reconocimiento jurisprudencial. Se deja de lado, por razones de espacio, el esclarecimiento de la relación entre derechos humanos y protección ambiental como tal ${ }^{4}$, aunque sí se tomarán en cuenta ciertos aspectos de esta relación en el análisis de las interacciones entre normas interestatales de protección ambiental y derechos humanos. Cabe resaltar, además, dos puntos. En primer lugar, a diferencia de lo que nos propusimos en nuestro texto del 2008, el presente estudio se basa en el análisis no solo de la jurisprudencia de la Corte Internacional de Justicia (CIJ) sino también de aquella de otros tribunales internacionales, en particular el Tribunal Internacional para el Derecho del Mar (TIDM) y los tribunales de arbitraje establecidos de conformidad con la Convención de Naciones Unidas para el Derecho del Mar (CONVEMAR) ${ }^{5}$. En segundo lugar, los principios en que se concentra el estudio no constituyen una mera selección dentro de la multitud de principios que podrían ser analizados, aun cuando estos hayan sido admitidos como tales por la prolífica y a veces excesivamente optimista doctrina ambientalista, sino que se estudian únicamente aquellos principios cuya base consuetudinaria no deja lugar a duda en el estado actual del Derecho internacional positivo. El análisis toma como punto de partida la jurisprudencia internacional por dos razones. Por una parte, dicha jurisprudencia ofrece un medio privilegiado de determinación de las reglas consuetudinarias, aunque técnicamente, como lo ha recalcado el reciente trabajo de codificación de la Comisión de Derecho Internacional $(\mathrm{CDI})^{6}$, un análisis amplio y específico de la práctica de los Estados —presupuesto en los desarrollos jurisprudenciales - sea el único método fidedigno. Por otra parte, el reconocimiento jurisprudencial ocupa un papel eminente en la práctica del contencioso internacional, por lo cual es legítimo referirse a dicho reconocimiento de modo prioritario.

Dentro de estos parámetros, el presente estudio se concentra en los tres principios u obligaciones principales en materia de protección ambiental, a saber: el principio de prevención en el marco de la diligencia debida, la obligación de cooperación y la exigencia de una evaluación de impacto ambiental. En la primera sección, se brinda una síntesis de la matriz consuetudinaria de la protección ambiental identificada por la jurisprudencia. Se analizan

vironmental Law», en TAMS, C. y SLOANE, R. (eds.), The Development of International Law by the International Court of Justice, Oxford University Press, 2013, cap. 15, y BoYLE, A. y HARRISON, J., «Judicial Settlement of International Environmental Disputes: Current Problems», Journal of International Dispute Settlement, vol. 4, 2013, pp. 245-276.

4 Véanse DupuY, P.-M. y ViñuALES, J. E., International Environmental Law, Cambridge, Cambridge University Press, 2015, capítulo 10, y BoYLE, A., "Human Rights and the Environment: Where Next?», EJIL, vol. 23, 2012, pp. 613-642.

${ }_{5}$ Convención de las Naciones Unidas sobre el Derecho del Mar, 10 de diciembre de 1982, 1834 UNTS 371 .

6 Véanse los cuatro informes presentados por el Relator Especial, Sir Michael Wood, sobre la cuestión de la identificación del Derecho consuetudinario internacional, disponibles en la Guía Analítica de la CDI: véase http://legal.un.org/ilc/guide/1_13.shtml (consultada el 15 de enero de 2017). 
luego cada uno de los tres principios que conforman dicha matriz así como sus interrelaciones. Se concluye con una breve referencia a ciertas dificultades que se plantean actualmente a nivel teórico y práctico en esta materia.

\section{SÍNTESIS DE LA MATRIZ CONSUETUDINARIA IDENTIFICADA POR LA JURISPRUDENCIA}

En el marco de los litigios entre Costa Rica y Nicaragua relativos a diversas actividades en el río San Juan, decididos de modo acumulado por la CIJ en su decisión del 16 de diciembre de 2015, la CIJ sintetiza en un párrafo la matriz consuetudinaria de las normas internacionales de protección ambiental:

"to fulfil its obligation to exercise due diligence in preventing significant transboundary environmental harm, a State must, before embarking on an activity having the potential adversely to affect the environment of another State, ascertain if there is a risk of significant transboundary harm, which would trigger the requirement to carry out an environmental impact assessment [...] If the environmental impact assessment confirms that there is a risk of significant transboundary harm, the State planning to undertake the activity is required, in conformity with its due diligence obligation, to notify and consult in good faith with the potentially affected State, where that is necessary to determine the appropriate measures to prevent or mitigate that risk» ${ }^{7}$.

Este párrafo es particularmente útil porque al mismo tiempo: i) identifica las normas a las que se les reconoce valor consuetudinario (la exigencia de diligencia debida de modo amplio así como en el marco del principio de prevención, y sus expresiones procedimentales, a saber la obligación de cooperación de buena fe, en particular por medio de la notificación y la consulta, y la exigencia de efectuar una evaluación previa de impacto ambiental), y ii) se refiere a los precedentes jurisprudenciales en los que la base consuetudinaria ha sido reconocida con anterioridad, en particular la decisión de la CIJ en el caso de las Papeleras en el Río Uruguay, entre Argentina y Uruguay ${ }^{8}$, decisión que, a su vez, se refiere a diversas decisiones anteriores ${ }^{9}$, prueba de las raíces

\footnotetext{
7 Certain activities carried out by Nicaragua in the Border Area (Costa Rica v. Nicaragua), Construction of a road in Costa Rica along the river San Juan (Nicaragua v. Costa Rica), Judgment of 16 December 2015, párr. 104 (en adelante, Costa Rica y Nicaragua).

8 Pulp Mills on the River Uruguay (Argentina v. Uruguay), Judgment, ICJ Reports 2010, p. 14, párr. 101 (relaciones entre la diligencia debida y la prevención); párr. 102 (obligación de cooperación como expresión de la prevención); párrs. 144-146 (obligación de cooperación de buena fe, en particular en relación con el desarrollo de las consultas entre Estados potencialmente afectados); y párr. 204 (evaluación previa de impacto ambiental) (en adelante, Papeleras en el Río Uruguay).

9 Corfu Channel Case, Judgment of 9 April 1949, ICJ Reports 1949, p. 4, p. 22 (referencia a la diligencia debida del Estado fuera del marco ambiental) (en adelante, Estrecho de Corfú); Legality of the Threat or Use of Nuclear Weapons, Advisory Opinion, ICJ Reports 1996, p. 226, párr. 29 (reconocimiento del carácter consuetudinario del principio de prevención del daño ambiental) (en adelante, Legalidad de las Armas Nucleares); Nuclear Tests (Australia v. France) (New Zealand v. France), Judgments, ICJ Reports 1974, p. 268, párr. 46 y p. 473, párr. 49 (buena fe en el cumplimiento de las obligaciones internacionales) (en adelante, Ensayos Nucleares); Border and Transborder Armed Actions (Nicaragua v. Honduras),
} 
profundas de las normas identificadas. Estos precedentes serán analizados en relación con cada una de las normas mencionadas.

Aspectos de dicha matriz también han sido reconocidos específicamente en el ámbito del Derecho del mar por la Sala de Controversias de los Fondos Marinos del TIDM ${ }^{10}$, el TIDM mismo ${ }^{11}$, así como por un tribunal de arbitraje ${ }^{12}$ constituido según el Anexo VII de la CONVEMAR. Cabe resaltar que en el caso Filipinas c. China ${ }^{13}$, así como en una ordenanza sobre medidas cautelares y en una opinión consultiva adoptadas por el TIDM ${ }^{14}$, la aplicación de las normas consuetudinarias de protección ambiental fue afirmada a pesar de que el título y los derechos soberanos sobre ciertos espacios marítimos fuesen litigiosos. La protección del medio ambiente es un deber objetivo que incumbe a todos los Estados. La aplicación de las normas ambientales recogidas en la Parte XII de la CONVEMAR no depende de cuestiones de soberanía o de derechos soberanos ${ }^{15}$. A fortiori, la aplicación de las normas

Jurisdiction and Admissibility, Judgment, ICJ Reports 1988, p. 105, párr. 94 (buena fe) (en adelante, Nicaragua c. Honduras); y North Sea Continental Shelf (Federal Republic of Germany/Denmark; Federal Republic of Germany/Netherlands), Judgment, ICJ Reports 1969, p. 47, párr. 85 (obligación de negociar de buena fe) (en adelante, Plataforma Continental del Mar del Norte).

10 Responsibilities and obligations of States sponsoring persons and entities with respect to activities in the Area, Advisory Opinion of 1 February 2011, ITLOS Case No. 17, párrs. 131-135 (donde se afirma que el principio de precaución puede ser considerado como una expresión de la obligación de diligencia debida e inclusive se sugiere su carácter consuetudinario independiente), y párr. 145 (carácter consuetudinario de la obligación de efectuar una evaluación previa de impacto ambiental, inclusive más allá de un contexto transfronterizo) (en adelante, Actividades en la Zona).

11 The MOX Plant Case, Ireland v. United Kingdom of Great Britain and Northern Ireland, Provisional Measures, ITLOS Case No. 10, Order of 3 December 2001, párr. 82 (donde se afirma el carácter consuetudinario de la obligación de cooperación) (en adelante, caso MOX Plant); Dispute Concerning Delimitation of the Maritime Boundary between Ghana and Côte d'Ivoire in the Atlantic Ocean (Ghana) Côte d'Ivoire), ITLOS Case No. 23, Order of 25 April 2015, párrs. 71 y 73 (donde se afirma el carácter consuetudinario del principio de prevención y de la obligación de cooperación) (en adelante, Costa de Marfil c. Ghana); y Request for an Advisory Opinion Submitted by the Sub-Regional Fisheries Commission (SRFC), Advisory Opinion of 2 April 2015, ITLOS Case No. 21, párr. 140 (donde se reafirma la base tanto convencional como consuetudinaria de la obligación de cooperación con referencia al caso $M O X$ Plant) (en adelante, Opinión Consultiva sobre las Pesquerías).

12 South China Sea Arbitration before an Arbitral Tribunal constituted under Annex VII of the United Nations Convention on the Law of the Sea (Republic of the Philippines v. People's Republic of China), PCA Case No. 2013-19, Award of 12 July 2016, párr. 941 (donde se vincula el contenido de la obligación de prevención del art. 192 de la CONVEMAR al Derecho consuetudinario ambiental); párrs. 946 y 984-985 (donde se hace referencia a los arts. 197 y 123 de la CONVEMAR relativos a la cooperación, inclusive en el ámbito de mares cerrados o semi-cerrados); y párrs. 947-948 (donde se hace referencia a los arts. 204 a 206 en relación con la obligación de efectuar una evaluación previa de impacto ambiental, sin limitación al contexto transfronterizo, y se la vincula al Derecho consuetudinario) (en adelante, Filipinas c. China).

13 Filipinas c. China, párr. 927.

${ }^{14}$ Costa de Marfil c. Ghana, párrs. 68-73 (de los que se deduce que el principio de prevención y la obligación de cooperación se aplican independientemente del carácter litigioso del área marítima en cuestión); y Opinión Consultiva sobre las Pesquerías, párrs. 111 y 120 (donde se afirma que la obligación formulada en el art. 192 de la CONVEMAR se aplica independientemente del tipo de espacio marítimo).

15 Filipinas c. China, pár. 940 ("At the outset, the Tribunal notes that the obligations in Part XII apply to all States with respect to the marine environment in all maritime areas, both inside the national jurisdiction of States and beyond it. Accordingly, questions of sovereignty are irrelevant to the application of Part XII of the Convention»). 
consuetudinarias en materia ambiental de contenido similar o más amplio no puede estar supeditada a dichas cuestiones.

\section{DILIGENCIA DEBIDA EN EL MARCO DEL PRINCIPIO DE PREVENCIÓN}

La formulación del principio de prevención que ha sido consagrada por la jurisprudencia es aquella de los principios 21 de la Declaración de Estocolmo sobre el Medio Humano ${ }^{16}$ y 2 de la Declaración de Río:

«De conformidad con la Carta de las Naciones Unidas y los principios del derecho internacional, los Estados tienen el derecho soberano de aprovechar sus propios recursos según sus propias políticas ambientales y de desarrollo, y la responsabilidad de velar por que las actividades realizadas dentro de su jurisdicción o bajo su control no causen daños al medio ambiente de otros Estados o de zonas que estén fuera de los límites de la jurisdicción nacional» ${ }^{17}$.

Esta formulación, posterior a la primera afirmación del principio en el caso de la Fundición de Trail ${ }^{18}$, ha sido amplia y sistemáticamente reconocida como expresión del Derecho internacional consuetudinario por la jurisprudencia internacional de diversos órganos ${ }^{19}$, entre los cuales la CIJ ${ }^{20}$, el TIDM $^{21}$ y varios tribunales de arbitraje ${ }^{22}$.

Nótese en la formulación del principio consuetudinario de prevención la extensión espacial de la norma, que se aplica tanto a daños al medio ambiente

16 «Declaración de Estocolmo sobre el Medio Humano», Informe de la Conferencia de las Naciones Unidas sobre el Medio Humano, Estocolmo, 5-16 de junio de 1972 (publicación de las Naciones Unidas, núm. de venta: S.73.II.A.14 y corrección), cap. 1.

17 Declaración de Río sobre el Medio Ambiente y el Desarrollo, Conferencia de las Naciones Unidas sobre el Medio Ambiente y el Desarrollo, Río de Janeiro, 3-14 de junio de 1992, Doc. ONU A/ CONF.151/26/Rev.1 (vol. I) (Declaración de Río), cursiva añadida (la formulación del principio 2 difiere de aquella del principio 21 de la Declaración de Estocolmo, ya que en Río se agregó la frase «y de desarrollo» luego de "políticas ambientales»).

18 Trail Smelter, RIAA, vol. III, pp. 1905-1982, p. 1965 («no State has the right to use or permit the use of its territory in such a manner as to cause injury by fumes in or to the territory of another or the properties or persons therein, when the case is of serious consequence and the injury is established by clear and convincing evidence») (en adelante, Fundición de Trail).

19 Sobre la práctica internacional y el reconocimiento jurisprudencial del principio de prevención: véase Duvic-Paoli, L.-A. y Viñuales, J. E., «Principle 2: Prevention», en Viñuales, J. E. (ed.), The Rio Declaration on Environment and Development. A Commentary, Oxford, Oxford University Press, 2015, pp. 107-138.

${ }^{20}$ Legalidad de las Armas Nucleares, párr. 29; Gabčíkovo-Nagymaros Project (Hungary/Slovakia), Judgment, ICJ Reports 1997, p. 7, párr. 140 (en adelante, Proyecto Gabčíkovo-Nagymaros); Papeleras en el Río Uruguay, párr. 101; y Costa Rica y Nicaragua, párrs. 104 y 118.

21 Costa de Marfil c. Ghana, párr. 71.

22 Indus Waters Kishenganga Arbitration before the Court of Arbitration constituted in accordance with the Indus Waters Treaty 1960 between the Government of India and the Government of Pakistan signed on 19 September 1960 (Islamic Republic of Pakistan v. Republic of India), PCA, Partial Award of 18 February 2013, párrs. 448-450 (donde se afirma la base consuetudinaria del principio de prevención desde el caso Fundición de Trail y su aplicación en el marco del diferendo, aunque se lo relacione con un pretendido "principio de desarrollo sostenible») (en adelante, Pakistán c. La India - Laudo parcial); y Filipinas c. China, párr. 941. 
«de otros Estados» como de «zonas que estén fuera de los límites de la jurisdicción nacional» (como el alta mar, los fondos marinos de la Zona, el espacio aéreo internacional o la Antártida). La jurisprudencia lo ha reconocido desde el inicio con dicha extensión espacial ${ }^{23}$.

Aunque la formulación aceptada del principio no emplee un adjetivo para calificar el daño ambiental, se entiende que se trata de un daño sensible («significant») ${ }^{24}$. Pero no hace falta que sea un daño grave o irreversible ${ }^{25}$. Las iniciativas internacionales de codificación de esta materia optaron deliberadamente por dejar la calificación del daño abierta, para que pueda ser decidida concretamente al nivel de la aplicación de la norma ${ }^{26}$.

En el caso Filipinas c. China, el tribunal de arbitraje se pronunció sobre el daño resultante tanto de la acción de pescadores bajo el control de China como de la construcción, directamente por parte de China, de grandes obras de infraestructura en el Mar de China Meridional. En ambos casos, el tribunal consideró el daño causado suficientemente sensible como para vulnerar el principio de prevención recogido en los arts. 192 y 194 de la CONVEMAR $^{27}$. En la primera situación, el tribunal observó que las actividades habían sido toleradas a pesar de que China había ratificado ciertos convenios internacionales, como el Convenio sobre la Diversidad Biológica $(\mathrm{CDB})^{28}$ y

23 Véanse Legalidad de las Armas Nucleares, párr. 29; Opinión Consultiva sobre las Pesquerías, párr. 120; y Filipinas c. China, párr. 940.

${ }^{24}$ Véase «Proyecto de artículos sobre la prevención del daño transfronterizo resultante de actividades peligrosas», Anuario CDI, vol. II, 2. ${ }^{a}$ parte, 2001, pp. 154 y ss. (en adelante, Proyecto de artículos sobre la prevención), art. 2(a); y Papeleras en el Río Uruguay, párr. 101.

25 Se exige que haya "peligro de daño grave o irreversible» en el marco del «criterio» (en inglés se habla del «approach») de precaución, según el principio 15 de la Declaración de Río. Véase igualmente el comentario al Proyecto de artículos sobre la prevención al art. 2, párr. 4 («[h]ay que entender que "sensible" es algo más que "detectable" pero sin necesidad de alcanzar el nivel de "grave” o "sustancial”»).

${ }^{26}$ Véase el comentario al Proyecto de artículos sobre la prevención al art. 2, párr. 4 («El término "sensible" no carece de ambigüedad, y habrá que precisarlo en cada caso en particular, lo que exigirá más consideraciones de hecho que determinaciones juridical»).

27 Filipinas c. China, párr. 941 (vinculando en art. 192 de la CONVEMAR al principio consuetudinario de prevención reconocido en la opinión consultiva de la CIJ sobre la Legalidad de la amenaza y el uso de armas nucleares); párr. 966 (concluyendo que China toleró las prácticas de los pescadores de ciertas especies protegidas internacionalmente y, por ende, violó los arts. 192 y 194.5 de la CONVEMAR); párr. 977 (el tribunal consideró, a la luz de un estándar de soft-law, que en la ausencia de medidas que impidan el uso de dinamita o de cianuro como método de pesca se estarían vulnerando los arts. 192, 194.2 y 194.5 de la CONVEMAR, pero agregó que no había suficientes pruebas para concluir que China había faltado a sus deberes); y párr. 977 (el tribunal concluye que los trabajos tendentes a construir islas artificiales en siete arrecifes de las islas Spratly causaron un daño «devastador y duradero — devastating and long-lasting — al medio ambiente marino, en violación de las obligaciones de China conforme a los arts. 192, 194.1 y 194.5 de la CONVEMAR»). Véanse también Pakistán c. La India - Laudo parcial, párrs. 448-449 (afirmando la aplicación del principio consuetudinario de prevención); Pakistán c. La India - Laudo final (20 de diciembre de 2013), párrs. 105-116 (donde se determina la cantidad de agua del río Indo que debía acordársele a Pakistán por medio de una estimación entre los derechos convencionales de la India y, entre otros factores, la protección del medio ambiente, en aplicación del principio de prevención, y se la fija a $9 \mathrm{~m}^{3}$ por segundo en lugar de los $12 \mathrm{~m}^{3}$ por segundo necesarios para una plena protección ambiental. La diferencia puede ser considerada como un daño tolerable —o no sensible- al medio ambiente).

${ }^{28}$ Convenio sobre la Diversidad Biológica, 5 de junio de 1992, 1760 UNTS 79. 
la Convención sobre el Comercio Internacional de Especies Amenazadas de Fauna y Flora Silvestres (CITES) ${ }^{29}$. La adopción por parte de China de legislación nacional para implementar estos instrumentos no fue considerada suficiente por el tribunal en la ausencia de iniciativas concretas tendentes a implementar dicha legislación. Por consiguiente, y a la luz de la existencia de obligaciones convencionales en materia ambiental, el tribunal concluyó que China no había cumplido con su diligencia debida ${ }^{30}$. Esta conclusión sugiere la posibilidad de un vínculo jurídico, aunque no automático, entre la violación de una obligación ambiental convencional y la determinación del carácter sensible del daño. En la segunda situación (construcción de islas artificiales), el daño resultante de las obras de infraestructura fue considerado «devastador y duradero ${ }^{31}$, lo que va claramente más allá del nivel requerido para calificar un daño de sensible.

Para esclarecer el nivel requerido de daño, también puede hacerse referencia a otros casos donde se evalúa la cuestión desde la perspectiva de su impacto sobre los derechos humanos de una persona física. Como menciona el comentario al trabajo de codificación de la CDI sobre la prevención del daño transfronterizo: «[e]l daño debe producir un efecto realmente perjudicial en esferas como, por ejemplo, la salud humana, la industria, los bienes, el medio ambiente o la agricultura de otros Estados. Esos efectos perjudiciales deben poder medirse con criterios reales y objetivos» ${ }^{32}$. La jurisprudencia de las cortes y comisiones regionales así como de los comités cuasi-jurisdiccionales establecidos por los tratados de derechos humanos exige un vínculo entre la degradación ambiental y la vulneración de un derecho humano ${ }^{33}$. En el caso López Ostra c. España, cuya importancia para el desarrollo ulterior del contencioso ambiental ante el Tribunal Europeo de Derechos Humanos (TEDH) es de conocimiento general, el TEDH consideró que una interferencia de naturaleza ambiental por parte de un tercero (humos, ruidos y malos olores emitidos por el funcionamiento de una planta de tratamiento de residuos sólidos y líquidos) era suficientemente sensible como para constituir una violación del derecho a la vida privada y familiar, previsto en el art. 8 del Convenio Europeo sobre Derechos Humanos ${ }^{34}$, aunque no lo fuese en relación con la salud de la demandante o de su familia:

«[n]aturally, severe environmental pollution may affect individuals' well-being and prevent them from enjoying their homes in such a way as to affect their

29 Convención sobre el Comercio Internacional de Especies Amenazadas de Fauna y Flora Silvestres, 3 de marzo de 1973, 983 UNTS 243.

30 Filipinas c. China, párrs. 962-966.

31 Ibid., párr. 977.

32 Comentario al Proyecto de artículos sobre la prevención, ad art. 2, párr. 4, cursiva añadida.

33 Véase Dupuy, P.-M. y Viñuales, J. E., nota 4, op. cit., pp. 320-324. Véase, por ejemplo, la exigencia de un vínculo entre la degradación ambiental y la situación individual de los demandantes en Kyrtatos c. Grecia, núm. 41666/98, párrs. 52-53, TEDH 2003; y Fadeyeva c. Rusia, núm. 55723/00, párrs. 68-70, TEDH 2005.

${ }^{34}$ Convenio para la protección de los derechos humanos y las libertades fundamentales, 4 de noviembre de 1950, 213 UNTS 221. 
private and family life adversely, without, however, seriously endangering their health» 35 .

A fortiori, un nivel de interferencia susceptible de menoscabar no solo el derecho a la vida privada y familiar sino también los derechos a la salud, a la integridad física o a la vida serían más que suficientes para que el daño ambiental fuese sensible ${ }^{36}$. Se debe recalcar que, en el caso López Ostra, el TEDH llegó a esta conclusión a pesar de que la interferencia en cuestión comportaba cierto interés público ${ }^{37}$.

Otro punto de gran importancia para el funcionamiento del principio de prevención es su relación con la diligencia debida no solo en el plano conceptual sino también, y ante todo, en el plano propiamente jurídico. Existen dos tipos de relación. En primer lugar, la obligación general de diligencia debida tiene un ámbito de aplicación que va más allá de la materia ambiental ${ }^{38}$ y recubre otras cuestiones tanto en las relaciones entre Estados como en aquellas entre un Estado y otras entidades. El principio de prevención constituye una expresión de esta norma amplia que exige un comportamiento diligente por parte de los Estados. En segundo lugar, la diligencia debida se manifiesta en el contexto específico del principio de prevención exigiendo que los Estados no solo se limiten a reparar el daño sensible causado al medio ambiente de otros Estados o de zonas que estén fuera de los límites de la jurisdicción nacional sino que también adopten, de modo proactivo, medidas de prevención de dicho daño y velen por su aplicación efectiva ${ }^{39}$.

La diligencia debida en el ámbito del principio de prevención comporta tanto una acción interna —el adoptar medidas de prevención y el velar a su aplicación efectiva- como una acción internacional -las diversas expresiones de la obligación de cooperación-. En el Derecho consuetudinario internacional (distinguiéndoselo a este respecto del Derecho internacional convencional), ciertos tipos de acción preventiva por parte del Estado donde se desarrolla una actividad riesgosa solo pueden ser exigidos de modo general (es decir, sin especificación de medidas y/o procesos particulares), mientras que otros tipos de acción preventiva pueden ser exigidos de modo específico por los Estados potencialmente afectados u otros actores (inter alia, la evaluación de impacto ambiental, la notificación y la consulta) ${ }^{40}$. El deber proactivo propio al principio de prevención exige ambos tipos de acción y por ende su ámbito - y los derechos correlativos que gozan los sujetos afectados- no

35 López. Ostra c. España, núm. 16798/90, párr. 51, TEDH 1994.

36 Véanse Oneryildiz c. Turquía, núm. 48939/99, párrs. 89-90, TEDH 2004 (dimensión ambiental de la protección del derecho a la vida); Budayeva y otros c. Rusia, núms. 15339/02, 21166/02, 20058/02, 11673/02 y 15343/02, párrs. 128-137, TEDH 2008 (donde se afirma la obligación del Estado de proteger el derecho a la vida de los individuos afectados por una catástrofe natural por intermedio de un deber proactivo de tomar medidas a este respecto).

37 López Ostra c. España, núm. 16798/90, párr. 58, TEDH 1994.

38 Estrecho de Corfú, p. 22.

39 Papeleras en el Río Uruguay, párr. 197; Actividades en la Zona, párr. 117; Opinión Consultiva sobre las Pesquerías, párr. 131; Pakistán c. La India - Laudo parcial, párr. 451; y Filipinas c. China, párr. 941.

40 Costa Rica y Nicaragua, párr. 104. 
se limita a los procedimientos específicos requeridos por normas específicas de Derecho internacional consuetudinario.

La acción preventiva exigida por el principio consuetudinario de prevención puede incluir toda una serie de medidas de manejo del riesgo inherente a ciertas actividades, lo que define una de las formas de articulación entre, por un lado, la norma consuetudinaria y, por otro lado, el Derecho interno así como el Derecho internacional convencional del Estado bajo el control del cual se desarrolla la actividad riesgosa ${ }^{41}$. La diligencia debida en el marco del principio de prevención puede, según las circunstancias, conllevar que dicho Estado se conforme a su Derecho interno y a sus obligaciones internacionales convencionales en todo ámbito de relevancia -inclusive fuera de lo que se entiende por Derecho ambiental (por ejemplo, los derechos humanos) — para la prevención del daño sensible al medio ambiente de otros Estados o de zonas que estén fuera de los límites de la jurisdicción nacional.

Debe subrayarse, sin embargo, que el deber proactivo de prevención del daño ambiental sensible es una obligación de medios y no de resultado ${ }^{42}$. De modo más específico, no existe en Derecho consuetudinario una responsabilidad objetiva por el mero acaecimiento de un daño ambiental sensible, en la ausencia de violación de un deber. El principio de prevención solo es vulnerado si el Estado en que se desarrolla la actividad en cuestión ha faltado a su deber proactivo de prevenir el daño ambiental sensible, en sus diversas manifestaciones. Puede suceder que dicho daño ocurra a pesar del alto nivel de diligencia del Estado en cuestión, por ejemplo, cuando el daño se debiese a la acción dolosa de un tercero que, a pesar de la existencia de un marco preventivo suficiente y de su aplicación diligente, no ha podido ser prevenido.

El deber de un Estado ( Estado de origen») de velar por que su territorio no sea utilizado de modo que se pueda causar un daño sensible al medio ambiente de otros Estados («Estado afectado») o de zonas que estén fuera de los límites de la jurisdicción nacional, acarrea diversos derechos correlativos. En particular, el Estado afectado tiene el derecho de invocar el principio de prevención para que el Estado de origen tome, mejore o implemente efectivamente medidas preventivas para evitar que el riesgo se materialice ${ }^{43} y$,

41 Véanse Papeleras en el Río Uruguay, párrs. 101-102 (donde se vincula la obligación consuetudinaria al sistema convencional de gestión del río Uruguay); y Actividades en la Zona, párrs. 117-120 y 127-150 (donde se vincula las obligaciones consuetudinarias de diligencia debida en el marco del principio de prevención, cooperación y evaluación de impacto ambiental al sistema de la CONVEMAR y a las reglas de la Autoridad de Fondos Marinos). Véanse, igualmente, la Opinión Consultiva sobre las Pesquerías, párrs. 131-140 (donde se vincula y se da contenido específico a la obligación de diligencia debida con base en las obligaciones convencionales de la CONVEMAR); y Filipinas c. China, párrs. 941942 (donde se vinculan las normas consuetudinarias de prevención, cooperación y de evaluación de impacto ambiental al sistema de la CONVEMAR, así como al de la CBD y CITES).

42 Papeleras en el Río Uruguay, párr. 187; Actividades en la Zona, párr. 110; y Opinión Consultiva sobre las Pesquerías, párr. 129.

43 Véase Papeleras en el Río Uruguay, párr. 197 ("[i]t is an obligation which entails not only the adoption of appropriate rules and measures, but also a certain level of vigilance in their enforcement and the exercise of administrative control applicable to public and private operators, such as the monitoring 
en caso de que un daño sensible haya sido causado, se cese la actividad y se repare el daño, de conformidad con las normas consuetudinarias en materia de responsabilidad internacional por hecho ilícito ${ }^{44}$. Además, desde el punto de los individuos basados en el Estado afectado («víctimas individuales») a quienes dicho daño cree un perjuicio, se abren diversas vías de acción que son relevantes para el análisis de la interacción entre normas ambientales y derechos humanos, como, por ejemplo, la posibilidad de actuar contra el Estado afectado por haber faltado al deber de brindar protección contra terceros (incluyendo al Estado de origen o a las entidades privadas presentes en su territorio) o también contra el Estado de origen en virtud de la extensión extraterritorial del ámbito de sus obligaciones en materia de derechos huma$\operatorname{nos}^{45}$. Como se verá en las secciones siguientes, el Estado afectado también puede exigir específicamente cierta conducta del Estado de origen en materia de cooperación y de evaluación de impacto ambiental.

\section{OBLIGACIÓN DE COOPERACIÓN DE BUENA FE}

El principio 19 de la Declaración de Río formula la obligación de cooperación en el ámbito ambiental en los términos siguientes:

«Los Estados deberán proporcionar la información pertinente y notificar previamente y en forma oportuna a los Estados que posiblemente resulten afectados por actividades que puedan tener considerables efectos ambientales transfronterizos adversos, y deberán celebrar consultas con esos Estados en una fecha temprana y de buena fe» ${ }^{46}$.

Los componentes de la obligación de cooperación formulada en el principio 19 han sido ampliamente reconocidos por la jurisprudencia internacional $^{47}$, en particular por la CIJ ${ }^{48}$, el TIDM ${ }^{49}$ y varios tribunales de arbitraje ${ }^{50}$.

of activities undertaken by such operators, to safeguard the rights of the other party"); y Actividades en la Zona, párr. 117 ("due diligence" is a variable concept. It may change over time as measures considered sufficiently diligent at a certain moment may become not diligent enough in light, for instance, of new scientific or technological knowledge. It may also change in relation to the risks involved in the activity [...] The standard of due diligence has to be more severe for the riskier activities»). Véase igualmente la Opinión Consultiva sobre las Pesquerías, párrs. 131-140.

${ }_{44}$ Proyecto de artículos sobre la Responsabilidad del Estado por hechos internacionalmente ilícitos, anexo a la Resolución 56/83 de la Asamblea General, 12 de diciembre de 2001, arts. 29-31.

45 Véase Viñuales, J. E., "A Human Rights Approach to Extraterritorial Environmental Protection? An Assessment», en BHutA, N. (ed.), The Frontiers of Human Rights. Extraterritoriality and its Challenges, Oxford, Oxford University Press, 2016, capítulo 6.

46 Declaración de Río, cursiva añadida.

47 Sobre la práctica internacional y el reconocimiento jurisprudencial en relación con este principio: véase Boisson de Chazournes, L. y Sangbana, K., «Principle 19: Notification and Consultation on Activities with Transboundary Impact», en VIÑUALES, J. E., nota 19, op. cit., pp. 493-507.

${ }^{48}$ Véanse, en orden cronológico, Estrecho de Corfú, p. 22; Plataforma Continental del Mar del Norte, párr. 85 (obligación de negociar de buena fe); Ensayos Nucleares, párrs. 46 y 49 (buena fe en el cumplimiento de las obligaciones internacionales); Papeleras en el Río Uruguay, párrs. 77 y 102 (obligación de cooperación como expresión de la prevención); párrs. 144-146 (obligación de cooperación de buena fe, en particular en relación con el desarrollo de las consultas entre Estados potencialmente afectados); y Costa Rica y Nicaragua, párr. 106 (obligación consuetudinaria de notificación y consulta). 
El funcionamiento de la obligación consuetudinaria de cooperación ha sido analizado por la jurisprudencia en relación con mecanismos específicos de cooperación establecidos por vía convencional ${ }^{51}$. Dichos mecanismos suelen especificar las modalidades de los componentes consuetudinarios de la obligación (por ejemplo, las circunstancias que desencadenan la obligación de notificación, el contenido de las comunicaciones requeridas, sus destinatarios, el plazo, el periodo mínimo o máximo por el cual se debe desarrollar la consulta). En ciertos casos, dichos mecanismos prevén obligaciones adicionales que no poseen una base consuetudinaria como, por ejemplo, la exigencia del consentimiento del Estado afectado por la actividad en cuestión ${ }^{52}$. A continuación, nos concentraremos únicamente en los componentes de naturaleza consuetudinaria.

Las circunstancias susceptibles de desencadenar la obligación de notificación y de consulta del Estado afectado por una actividad son de diversos órdenes. En su reciente decisión en el caso entre Costa Rica y Nicaragua, la CIJ afirmó el principio según el cual el riesgo de daño ambiental sensible en un contexto transfronterizo, confirmado por una evaluación de impacto ambiental, desencadena la obligación de notificar al Estado afectado ${ }^{53}$. También se desprende de este caso que, en la ausencia de dicho riesgo, aseverada por procedimientos internos requeridos por la diligencia debida en el marco del principio de prevención (por ejemplo, una evaluación preliminar o "preliminary assessment») ${ }^{54}$, no emerge la obligación consuetudinaria (exigible por los Estados afectados) de efectuar una evaluación de impacto ambiental o de notificar y consultar ${ }^{55}$. Sin embargo, como hemos señalado anteriormente, existe una diferencia entre, por un lado, la acción preventiva requerida

49 Caso MOX Plant, párr. 82 (carácter consuetudinario de la obligación de cooperación); Land Reclamation in and around the Straits of Johor (Malaysia v. Singapore), ITLOS Case No. 12, Order of 10 September 2003, párr. 92 (obligación de cooperación) (en adelante, Malasia c. Singapur); Costa de Marfil c. Ghana, párr. 73 (carácter consuetudinario de la obligación de cooperación); y Opinión Consultiva sobre las Pesquerías, párr. 140 (base consuetudinaria de la obligación de cooperación con referencia al caso MOX Plant).

50 Affaire du Lac Lanoux (France c. Espagne), sentence du 16 novembre 1957, RSA, vol. XII, pp. 281317, p. 308, párr. 13 (existencia de una obligación de cooperación para establecer acuerdos sobre recursos compartidos) (en adelante, Lago Lanós); y Filipinas c. China, párrs. 946 y 984-985 (donde se hace referencia a los arts. 197 y 123 de la CONVEMAR relativos a la cooperación, inclusive en el ámbito de mares cerrados o semi-cerrados).

51 Papeleras en el Río Uruguay, párrs. 144-147 (donde se vincula la obligación consuetudinaria al sistema convencional de cooperación del Estatuto del Río Uruguay); Opinión Consultiva sobre las Pesquerías, párrs. 139-140 (en que se vincula la obligación consuetudinaria de cooperación al contenido específico del art. 94.6 de la CONVEMAR); y Filipinas c. China, párrs. 946 y 984-985 (donde se hace referencia a los arts. 197 y 123 de la CONVEMAR relativos a la cooperación, inclusive en el ámbito de mares cerrados o semi-cerrados).

52 Lago Lanós, párrs. 13 y 22 (la ausencia en Derecho internacional general, ya sea como norma consuetudinaria o como principio general del Derecho, de una norma supeditando el desarrollo de proyectos susceptibles de tener un impacto transfronterizo al consentimiento previo del Estado potencialmente afectado. Dicha exigencia solo puede existir en virtud de un tratado).

53 Costa Rica y Nicaragua, párrs. 104, 108 y 168.

54 Ibid., párrs. 153-154.

55 Ibid., párr. 108. 
por el principio de prevención (por ejemplo, una evaluación preliminar), la cual no puede ser exigida de modo específico por otros Estados en Derecho consuetudinario y, por otro lado, los procedimientos específicos de acción preventiva (como la evaluación de impacto ambiental y las obligaciones de notificación y de consulta) que sí pueden ser exigidos de modo específico en virtud de normas consuetudinarias. La CIJ ha dejado muy en claro que si una evaluación de impacto ambiental establece la existencia de riesgo de daño ambiental sensible a otro Estado, el Derecho internacional consuetudinario exige la notificación y la consulta con dicho Estado ${ }^{56}$.

Pero la obligación de notificación y de consulta no se encuentra condicionada a la realización de una evaluación de impacto ambiental que asevere el riesgo de daño ambiental sensible. El elemento esencial que desencadena la obligación es la existencia de riesgo, la cual puede ser aseverada de varios modos. El deber de determinar dicho riesgo incumbe al Estado donde se planifican las actividades en cuestión, en el marco de la diligencia debida y de la buena fe. Es preciso recalcar que no se trata de un poder unilateral y discrecional de este Estado, ya que el elemento decisivo es el riesgo real. Puede suceder que el Estado de origen considere que no existe un riesgo suficiente y, por ende, no cumpla con los procedimientos específicos exigidos por el Derecho consuetudinario. Pero ello no exime a dicho Estado de sus obligaciones ${ }^{57}$. Llegado el caso, un tribunal internacional podrá establecer que existía un riesgo suficiente y que, por su acción deficiente, el Estado en cuestión ha vulnerado sus obligaciones internacionales ${ }^{58}$.

La necesidad de evaluar el riesgo, en virtud del principio de prevención, debe ser interpretada a luz de ciertos estándares que pueden variar con el tiempo y el desarrollo tecnológico, como lo requiere la diligencia debida. Generalmente, para enmarcar el ejercicio del deber de evaluación del riesgo, se utilizan técnicas como la identificación de tipos de actividad que por su naturaleza y alcance implican un riesgo suficiente (por ejemplo, refinerías de petróleo crudo, ciertas centrales termoeléctricas, autopistas y vías férreas, puertos comerciales, oleoductos y gasoductos de gran diámetro, grandes presas y embalses, producción de hidrocarburos frente a la costa, y otras) ${ }^{59}$ o de objetos jurídicos cuyas particularidades requieren la cooperación entre Estados (por ejemplo, áreas particularmente frágiles o recursos

56 Ibid., párrs. 104, 108 y 168.

57 En el caso relativo al Lago Lanós, el tribunal de arbitraje subrayó que el eventual impacto sobre un país limítrofe no puede, en ningún caso, quedar librado a la apreciación exclusiva del Estado que desarrolla las actividades en cuestión: véase Lago Lanós, p. 314, párr. 21.

58 En el caso entre Costa Rica y Nicaragua, la CIJ consideró, basándose en las pruebas aducidas, que la construcción de una ruta por parte de Costa Rica presentaba un riesgo significativo que habría exigido que Costa Rica efectúe una evaluación de impacto ambiental previamente a los trabajos de construcción (Costa Rica y Nicaragua, párrs. 155-156). Con arreglo a esta conclusión, la CIJ no consideró necesario pronunciarse sobre la violación por Costa Rica de la obligación de notificación y de consulta (párr. 168), sin duda por razones de economía procesal.

59 Véase el Convenio de la Comisión Económica para Europa de las Naciones Unidas sobre la evaluación del impacto ambiental en un contexto transfronterizo, 25 de febrero de 1991, doc. ONU ECE/ ENHS/NONE/2003/25, Anexo 1. 
compartidos $)^{60}$. Aunque se trate en dichos casos de sistemas convencionales, estos sistemas son relevantes para evaluar tanto el nivel de diligencia como la buena fe. Es así, por ejemplo, por lo que una evaluación unilateral basada en estándares obsoletos o claramente inadecuados, o que concluya de modo sumario que una actividad a la que se le reconoce generalmente un alto nivel de riesgo no acarrea ningún riesgo transfronterizo ${ }^{61}$ faltaría a los estándares de diligencia debida y/o a la buena fe. En dicho caso, las obligaciones consuetudinarias específicas que exigen la realización de una evaluación de impacto ambiental, así como la notificación y la consulta serían exigibles por parte de Estados afectados.

La obligación consuetudinaria de notificación incumbe al Estado de origen y no es suficiente que la información se encuentre disponible públicamente en los medios de comunicación ${ }^{62}$ o que dicha notificación haya sido efectuada por parte de una empresa o de otra entidad privada, a pesar de que esta última esté a cargo del proyecto en cuestión ${ }^{63}$. Ello atiende al objetivo de la obligación de notificación que es el de informar suficientemente y oficialmente a los Estados afectados acerca de la situación con el fin de continuar el proceso de cooperación ${ }^{64}$.

Dicho objetivo también conlleva que los destinatarios de la notificación sean aquellas entidades que estarán involucradas en el proceso de cooperación. Naturalmente, ello incluye a los Estados afectados pero también puede requerir que se notifique a ciertos organismos internacionales ${ }^{65}$.

El objetivo de cooperación es también determinante con respecto al momento y al contenido de la notificación exigida por la obligación consuetudinaria. La norma consuetudinaria no posee el detalle que pueden brindar a este respecto los sistemas convencionales, pero el objetivo de la norma implica necesariamente que se notifique con suficiente antelación (el principio 19 utiliza los términos "previamente y en forma oportuna») ${ }^{66}$ y se brinde la información suficiente («información pertinente») ${ }^{67}$ para que el proceso de cooperación tenga pleno sentido o, como lo menciona el principio 19, para posibilitar «consultas con esos Estados [afectados] en una fecha temprana y de buena fe».

${ }^{60}$ Véanse Papeleras en el Río Uruguay, párrs. 75-77 (en relación con el aprovechamiento conjunto del río Uruguay); y Costa Rica y Nicaragua, párr. 109 (donde la CIJ se refiere a obligaciones procedimentales adicionales en relación con humedales transfronterizos, aunque dichas obligaciones no hayan sido consideradas como aplicables in casu).

${ }^{61}$ Filipinas c. China, párr. 988.

${ }^{62}$ Véase Certain Questions of Mutual Assistance in Criminal Matters (Djibouti v. France), ICJ Reports 2008, p. 231, párr. 150.

${ }^{63}$ Papeleras en el Río Uruguay, párr. 110.

${ }^{64}$ Ibid., párrs. 113 y 115.

65 Véanse Papeleras en el Río Uruguay, párrs. 90, 119 y 121; y Costa Rica y Nicaragua, párr. 109 (donde la CIJ reconoce la existencia de una obligación convencional de notificar la Secretaría del Convenio de Ramsar sobre Humedales de Importancia Internacional, pero rechaza su aplicación in casu dada la ausencia de impacto considerable de las actividades de Nicaragua).

${ }^{66}$ Véanse Proyecto de artículos sobre la prevención, art. 8.1; y Papeleras en el Río Uruguay, párr. 120.

67 Véase Papeleras en el Río Uruguay, párr. 120. 
Para que el proceso de consulta cumpla con las exigencias de la buena fe, es necesario que no se limite a meros trámites formales. Como lo afirmó el tribunal de arbitraje en el caso del Lago Lanós:

"l'Etat d'amont a, d'après les règles de la bonne foi, l'obligation de prendre en considération les différents intérêts en présence, de chercher à leur donner toutes les satisfactions compatibles avec la poursuite de ses propres intérêts et de montrer qu'il $a$ à ce sujet, un souci réel de concilier les intérêts de l'autre riverain avec les siens propres. Il est délicat d'apprécier s'il a été satisfait à une telle obligation. Mais, sans se substituer aux Parties, le juge est en mesure de procéder à cette appréciation sur la base des éléments fournis par les négociations» ${ }^{6 .}$

Cabe resaltar que la obligación de cooperación no equivale a exigir el consentimiento del Estado afectado. Pero la exigencia de cooperar de buena fe no se ve, por tanto, privada de contenido. Por el contrario, dicha exigencia comporta consecuencias concretas, susceptibles de ser evaluadas judicialmente si ello fuera necesario. Es así que en el caso Filipinas c. China, el tribunal de arbitraje juzgó a la luz de las pruebas aducidas que, en sus actividades de construcción de islas artificiales, China había faltado a su obligación de cooperación ${ }^{69}$. Otra consecuencia concreta, afirmada por la CIJ en el caso de las Papeleras en el Río Uruguay, es que mientras se desarrollen las consultas entre los Estados involucrados, se faltaría a la buena fe y se vulneraría la obligación de cooperación si el Estado de origen otorgara unilateralmente la autorización a una entidad privada para que comenzara o prosiguiera sus actividades ${ }^{70}$.

\section{EXIGENCIA DE UNA EVALUACIÓN DE IMPACTO AMBIENTAL}

El principio 17 de la Declaración de Río formula la exigencia de efectuar una evaluación de impacto ambiental:

«Deberá emprenderse una evaluación del impacto ambiental, en calidad de instrumento nacional, respecto de cualquier actividad propuesta que probablemente haya de producir un impacto negativo considerable en el medio ambiente y que este sujeta a la decisión de una autoridad nacional competente» ${ }^{71}$.

El carácter consuetudinario de dicha exigencia ${ }^{72}$ ha sido reconocido tanto por la $\mathrm{CIJ}^{73}$ como por otras jurisdicciones internacionales ${ }^{74}$.

68 Lago Lanós, p. 315, párr. 22 («de conformidad con las reglas de la buena fe, el Estado aguas arriba tiene la obligación de tomar en cuenta los diferentes intereses en cuestión, de intentar satisfacerles en toda la medida que sea compatible con la satisfacción de su propio interés y de demostrar que se preocupa verdaderamente por conciliar los intereses del otro Estado ribereño con los suyos. Es delicado apreciar si se ha cumplido con dicha obligación. Pero el juez puede, sin por ello sustituirse a las Partes, proceder a dicha apreciación en base a los elementos brindados por la negociación», nuestra traducción).

69 Filipinas c. China, párr. 986.

70 Papeleras en el Río Uruguay, párr. 144.

71 Declaración de Río, cursiva añadida.

72 Sobre la práctica internacional y el reconocimiento jurisprudencial de esta exigencia véase CRAIK, N., «Principle 17: Environmental Impact Assesment», en ViñUALES, J. E., nota 19, op. cit., pp. 451-470.

(Véanse notas 73 y 74 en página siguiente) 
La obligación incumbe al Estado de origen en caso de que una «actividad» propuesta y «sujeta a la decisión de una autoridad nacional competente» que "probablemente haya de producir un impacto negativo considerable». La norma se refiere específicamente a actividades, y no a políticas públicas o planes ${ }^{75}$, y dichas actividades deben estar sujetas en virtud del Derecho interno a una aprobación del Estado. Sin embargo, el Estado de origen no puede eludir la obligación de efectuar una evaluación impacto ambiental simplemente evitando someter ciertas actividades a su aprobación, ya que ello vulneraría la diligencia debida en el marco del principio de prevención. El factor determinante es la existencia objetiva de cierto tipo de riesgo, saber de un riesgo de daño ambiental considerable.

Ya se ha hecho referencia a la caracterización del adjetivo «sensible» así como a las circunstancias susceptibles de desencadenar la obligación de cooperación. El empleo del término «considerable» en la versión española del principio 17 y no del adjetivo «sensible», como en el marco del principio de prevención, puede prestarse a malentendidos. La CIJ ha reconocido el carácter consuetudinario de esta exigencia en caso de riesgo de «significant adverse impact» ${ }^{76}$, que son también los términos empleados en la versión inglesa del principio 17 así como en el Proyecto de artículos sobre la prevención. Ello sugiere que se trata del mismo nivel de daño que el llamado daño «sensible» en el marco del principio de prevención. Sin embargo, la versión francesa - como la española - introduce ciertas dudas, ya que se utiliza una terminología variable. En el principio 17 se habla de "effets nocifs importants» $\mathbf{y}$ en la versión francesa de su fallo, la CIJ se refiere a un «impact préjudiciable important», mientras que el texto francés del Proyecto de artículos sobre la prevención califica el daño de "significatif». La CIJ menciona que la ausencia de evaluación de impacto ambiental cuando la obra que se planea podría afectar al régimen de un río o a la calidad de sus aguas vulneraría además el principio de prevención ${ }^{77}$, pero la relación específica entre estos diversos adjetivos no queda del todo clara. Se abren, entonces, dos vías posibles. Por una parte, podría entenderse que el nivel de daño susceptible de vulnerar el principio de prevención es el mismo que aquel que desencadena la exigencia de evaluación de impacto ambiental. Por otra parte, podría considerarse que

73 Papeleras en el Río Uruguay, párr. 204 (estudio previo de impacto ambiental, en un contexto transfronterizo); y Costa Rica y Nicaragua, párr. 104 (afirmación de la exigencia, en referencia al caso de las Papeleras en el Río Uruguay).

74 Actividades en la Zona, párr. 145 (carácter consuetudinario de la obligación de efectuar una evaluación previa de impacto ambiental, inclusive mas allá de un contexto transfronterizo); y Filipinas c. China, párrs. 947-948 (donde se hace referencia a los arts. 204-206 de la CONVEMAR en relación con la obligación de efectuar una evaluación de impacto ambiental, sin limitación al contexto transfronterizo, y se la vincula al Derecho consuetudinario).

75 La práctica internacional establece una clara distinción entre, por una parte, la evaluación del impacto ambiental de «actividades» y, por otra parte, de «planes o políticas públicas». Estas últimas, que pueden incluir también la negociación de tratados internacionales en materia comercial, no se encuentran sujetas, por el momento, a la obligación consuetudinaria de efectuar una evaluación previa de impacto ambiental. Véase CRAIK, N., nota 72, op. cit., p. 456.

76 Papeleras en el Río Uruguay, párr. 204.

77 Ibid. 
el daño «sensible» es una categoría más amplia que la de daño considerable (o que los «effets nocifs importants» o el «impact préjudiciable important») o, dicho de otro modo, que el daño considerable requiere algo más que el daño sensible. En el caso entre Costa Rica y Nicaragua, la CIJ se pronunció específicamente sobre el nivel de daño susceptible de desencadenar la exigencia de evaluación de impacto ambiental y las dos versiones del fallo mantienen la ambigüedad. En efecto, mientras que la versión inglesa habla de «risk of significant transboundary harm» la versión francesa se refiere a un "risque de dommage transfrontière important» ${ }^{78}$.

A nuestro entender, la segunda posición sería conforme a la tesis que expusimos según la cual la diligencia debida en el marco del principio de prevención acarrea obligaciones correlativas generales, mientras que para exigir ciertas medidas o procedimientos de manera específica hace falta una norma específica, a saber la exigencia de una evaluación de impacto ambiental basada en la importancia particular del riesgo de daño. La necesidad de evaluar el impacto ambiental de modo general forma parte tanto de la diligencia debida en el marco del principio de prevención, como de la obligación de cooperación. Pero el elemento determinante que hace surgir la obligación específica de efectuar una evaluación de impacto ambiental y la vuelve exigible, en virtud del Derecho internacional consuetudinario, es la probabilidad de un impacto negativo considerable o, en otros términos, la existencia de riesgo de daño ambiental considerable, no solo sensible. Como ya se ha señalado, dicha existencia es un elemento objetivo y no meramente discrecional ${ }^{79}$. Tal riesgo debe ser presumido en relación con ciertas actividades, en razón de su naturaleza y alcance (grandes obras de infraestructura) ${ }^{80}$, o con ciertos objetos de protección (áreas particularmente frágiles o recursos compartidos). También puede determinarse la existencia de dicho riesgo por medio de un estudio preliminar ${ }^{81}$. Ambas técnicas permiten resolver el problema de circularidad que existiría si se afirmara que la exigencia de una evaluación de impacto ambiental solo surge cuando existe riesgo de daño ambiental considerable aseverado por medio de una evaluación de impacto ambiental.

El daño susceptible de ser causado por la actividad en cuestión puede afectar al «medio ambiente de otros Estados» o a aquel de "zonas que estén fuera de los límites de la jurisdicción nacional» como lo prevé el principio consuetudinario de prevención. Dicha extensión espacial se encuentra implícita en la formulación del Principio 17 de la Declaración de Río, pero ha sido además confirmada por la jurisprudencia internacional, la cual ha afirmado la exigencia de una evaluación de impacto ambiental tanto en un contexto transfronterizo ${ }^{82}$ como en relación con áreas fuera de los límites de la jurisdicción nacional, como los fondos marinos de la Zona ${ }^{83} \mathrm{o}$ el alta mar ${ }^{84}$.

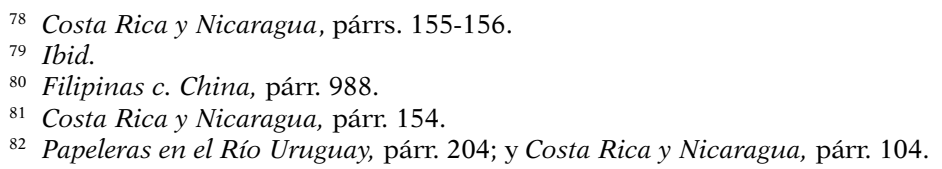


El contenido de la evaluación de impacto ambiental, de conformidad con la norma consuetudinaria, debe ser apropiado al tipo de actividad en cuestión. La CIJ ha considerado que incumbe al Estado de origen la determinación, por medio de su Derecho interno, del contenido específico de la evaluación de impacto ambiental ${ }^{85}$. Pero dicha determinación no es meramente unilateral y discrecional ya que debe incluir ciertos parámetros fijados por el Derecho internacional consuetudinario y también respetar la diligencia debida en el marco del principio de prevención, así como la obligación de cooperar de buena fe.

En relación con los parámetros consuetudinarios, la jurisprudencia considera, por razones de diligencia debida en el marco del principio de prevención, y en virtud de la obligación de cooperar de buena fe, que dicha evaluación debe ser "previa» a la autorización o a fortiori al desarrollo de la actividad ${ }^{86}$. Además, la CIJ ha afirmado en dos oportunidades que la evaluación de impacto ambiental implica que se monitoree de modo continuo dicho impacto durante el desarrollo de la actividad ${ }^{87}$. Ello es conforme a la diligencia debida que apunta a prevenir el daño ambiental sensible que pueda resultar de la actividad, aunque este no haya sido anticipado satisfactoriamente por la evaluación previa ${ }^{88}$.

En lo atinente a los límites generales impuestos por la diligencia debida en el marco del principio de prevención y por la obligación de cooperar de buena fe, la jurisprudencia internacional ha afirmado en varias oportunidades que el contenido de la evaluación de impacto ambiental debe ser apropiado con respecto a las circunstancias de la actividad propuesta. En efecto, la CIJ ha considerado que:

«it is for each State to determine in its domestic legislation or in the authorization process for the project, the specific content of the environmental impact assessment required in each case, having regard to the nature and magnitude of the proposed development and its likely adverse impact on the environment as well as to the need to exercise due diligence in conducting such an assessment» ${ }^{89}$.

${ }^{83}$ Actividades en la Zona, párrs. 145 y 148.

${ }^{84}$ Filipinas c. China, párrs. 947-948.

${ }_{85}$ Papeleras en el Río Uruguay, párr. 205.

86 Ibid. ("The Court also considers that an environmental impact assessment must be conducted prior to the implementation of a project»); y Costa Rica y Nicaragua, párr. 161 ("the obligation to conduct an environmental impact assessment requires an ex ante evaluation of the risk of significant transboundary harm»).

87 Papeleras en el Río Uruguay, párr. 205; y Costa Rica y Nicaragua, párr. 161.

88 Según un estudio comparativo de las evaluaciones de impacto ambiental previstas en la legislación de diversos países, la incapacidad de dichas evaluaciones de anticipar efectivamente el daño ambiental, aun en aquellos casos en que la evaluación se ha desarrollado de conformidad con la reglamentación vigente, es uno de los mayores desafíos que las iniciativas de reforma deben responder en la actualidad. Véase RETIEF, F. et al., "Global megatrends and their implications for environmental assessment practice», Environmental Impact Assessment Review, vol. 61, 2016, pp. 52-60, pp. 55-56 (donde se explica que la complejidad de problemáticas como el cambio climático limita el impacto predictivo de las evaluaciones de impacto ambiental).

89 Papeleras en el Río Uruguay, párr. 205. 
Ello ha sido confirmado por la CIJ en el caso entre Costa Rica y Nicaragua ${ }^{90}$.

La adecuación de ciertos procedimientos al nivel requerido por la diligencia debida puede ser revisada por un tribunal internacional y, según el caso, este puede concluir que un Estado ha faltado a sus obligaciones internacionales. Es así que la CIJ consideró que Costa Rica había vulnerado la exigencia consuetudinaria de efectuar una evaluación de impacto ambiental previamente al comienzo de las actividades de construcción de una ruta a lo largo del río San Juan ${ }^{91}$ y que dicha conducta no podía ser justificada por las circunstancias del caso, ya que no podía comprobarse el pretendido estado de emergencia alegado por Costa Rica ${ }^{92}$. De modo similar, en el caso Filipinas c. China, el tribunal de arbitraje se refirió a la decisión de la CIJ en el caso entre Costa Rica y Nicaragua y consideró no solo que la mera afirmación de la realización de una evaluación de impacto ambiental es insuficiente para cumplir con la obligación convencional y consuetudinaria sino que, además, los estudios que el tribunal pudo identificar no eran conformes a los estándares usuales ${ }^{93}$.

Por otra parte, en ciertas circunstancias, la información necesaria para que una evaluación de impacto ambiental sea suficiente puede encontrarse en manos de otros Estados o inclusive de individuos. No permitir la participación de dichos Estados o individuos o discriminar entre ellos implicaría no solo una violación de la diligencia debida sino también, potencialmente, de la obligación de cooperación. No toda situación de hecho comportará esta dimensión adicional ${ }^{94}$ y, por ende, el proceso de evaluación de impacto ambiental no siempre implica de modo necesario la participación de entidades extranjeras. Pero en ciertos casos dicha participación será esencial para que la evaluación de impacto ambiental cumpla con las exigencias de la diligencia debida en el marco del principio de prevención y de la obligación de cooperar de buena fe, lo que conlleva inter alia la obligación de notificar y consultar a los Estados afectados durante la evaluación, así como la integración de otras partes interesadas. Como se verá a continuación, a modo de conclusión, las cuestiones planteadas en este párrafo permiten entrever tres desafíos actuales de gran importancia.

90 Costa Rica y Nicaragua, pár. 104 ( $D$ Determination of the content of the environmental impact assessment should be made in light of the specific circumstances of each case»).

91 Ibid., párr. 161.

92 Ibid., párrs. 157-159. Nótese que, en el párr. 157, la CIJ afirma claramente los límites a la discrecionalidad del Estado ("the fact that there may be an emergency exemption under Costa Rican law does not affect Costa Rica's obligation under international law to carry out an environmental impact assessment»).

93 Filipinas c. China, párrs. 988-990 (en este último párrafo se menciona lo siguiente: «The SOA Statement and the SOA Report which the Tribunal did manage to locate both fall short of these criteria, and are far less comprehensive than EIAs reviewed by other international courts and tribunals, or those filed in the foreign construction projects to which the SOA scientists referred in their report»).

94 Costa Rica y Nicaragua, párrs. 104, 108 y 168. 


\section{DESAFíos ACTUALES}

Volver, a modo de conclusión, al punto de partida del presente estudio, a saber el caso entre Costa Rica y Nicaragua, permite formular de manera concisa la matriz consuetudinaria en materia de protección ambiental y, al mismo tiempo, señalar las dificultades que se plantean actualmente. En efecto, como se observó anteriormente, el Derecho consuetudinario en este ámbito reposa en la exigencia de diligencia debida en el marco del principio de prevención, y sus expresiones procedimentales, a saber: la obligación de cooperación de buena fe, en particular por medio de la notificación y la consulta, y la exigencia de efectuar una evaluación previa de impacto ambiental. Pero al mismo tiempo, esta formulación deja abiertas tres cuestiones importantes.

En primer lugar, en el caso entre Costa Rica y Nicaragua, la CIJ introdujo una secuencia problemática entre dichas normas. Según la Corte, la obligación de notificar y consultar solo surge una vez que la evaluación de impacto ambiental ha confirmado un riesgo transfronterizo. Pero ello crea ciertas ambigüedades con respecto a las exigencias de la obligación de cooperación antes de que se realice la evaluación de impacto ambiental. En efecto, dado el carácter general de la obligación de cooperación en el Derecho internacional, no puede considerarse que la cooperación se limite únicamente a dos pasos procedimentales (notificación y consulta) supeditados a un tercero (evaluación de impacto ambiental). En realidad, la realización misma de una evaluación de impacto ambiental o aun del paso procedimental previo (por ejemplo, un estudio preliminar) puede requerir cierto nivel de cooperación internacional, por ejemplo, en relación con recursos compartidos, entre otras hipótesis.

En segundo lugar, la diferencia entre el ámbito amplio de la obligación de cooperación y ciertas de sus expresiones específicas también es pertinente para el principio de prevención. En efecto, la diligencia debida en el marco del principio de prevención exige la adopción proactiva y la aplicación diligente de medidas de prevención. Algunas de ellas se han cristalizado en normas individuales (cooperación —que a su vez posee expresiones específicas - y evaluación de impacto ambiental — que puede ser un modo de coope-

rar-), pero existen muchas otras que todavía no han llegado a ese estadio de individuación y que, sin embargo, forman parte de las exigencias consuetudinarias. Un ejemplo básico es la obligación de determinar de modo diligente y de buena fe (por ejemplo, por vía de un estudio preliminar) si una evaluación de impacto ambiental es necesaria para aseverar la existencia de riesgo de daño considerable. El proceso de especificación de las medidas exigidas - por el momento de modo general- por la diligencia debida en el marco del principio de prevención es de particular importancia ya que permitiría contrarrestar ciertos puntos débiles en la normativa consuetudinaria. Tres ilustraciones pertinentes son las relacionadas: i) al marco decisional del Estado de origen de la actividad, el cual no es discrecional sino que está sujeto a 
la diligencia debida y a su eventual revisión judicial; ii) al gatillo que permite desencadenar la obligación consuetudinaria de evaluación de impacto ambiental (presunciones o estudios preliminares que indiquen riesgo de daño considerable, no solo sensible), y iii) al contenido mismo de dicha evaluación el cual, a pesar de ser delegado por la norma consuetudinaria al Derecho nacional, no es puramente discrecional, como se ha visto.

En tercer lugar, la especificación de las exigencias de la diligencia debida podrían desembocar, en un futuro no muy lejano, en el surgimiento o la consolidación de normas consuetudinarias cuyo estatus actual es objeto de debates, como, por ejemplo, el principio (o criterio) precautorio o el principio de participación pública en materia ambiental. Puede considerarse que estas normas forman parte de la diligencia debida, pero podrían afianzarse a un punto tal que su base consuetudinaria individual y distinta fuera reconocida de modo uniforme. Dado el reconocimiento jurisprudencial cada vez más decidido, no estamos lejos de esta consolidación, pero se trata de un tema que merece un estudio separado y específico.

Estas tres cuestiones están ligadas entre sí y el estatus doctrinal o propiamente jurídico de cada una de ellas es, sin duda, importante, pero lo es aún más la comprensión del camino que va del principio de prevención al detalle de la normativa internacional. Como lo escribiera Antonio Machado en su tan célebre poema, en estas cuestiones también se hace camino al andar.

\section{RESUMEN}

\section{LA PROTECCIÓN AMBIENTAL EN EL DERECHO CONSUETUDINARIO INTERNACIONAL}

El presente artículo analiza el estado actual del Derecho consuetudinario internacional en materia de protección ambiental. A través de un estudio pormenorizado de la jurisprudencia internacional pertinente, el artículo identifica una matriz consuetudinaria que consiste en la exigencia de diligencia debida en el marco del principio de prevención, y sus expresiones procedimentales, a saber: la obligación de cooperación de buena fe, en particular por medio de la notificación y la consulta, y la exigencia de efectuar una evaluación previa de impacto ambiental. Pese a que la doctrina haya afirmado el carácter consuetudinario de una multitud de principios, solo los identificados en este artículo han recibido una consagración jurisprudencial indiscutible. Por ende, el artículo no efectúa una mera selección de ciertos principios, sino que se concentra en aquellos cuya base consuetudinaria ha sido efectivamente reconocida. Se estudia luego el detalle de cada una de estas normas, así como sus interacciones. El artículo concluye con una breve referencia a la frontera actual en materia de desarrollo consuetudinario, recalcando las dificultades que se desprenden de la aplicación secuencial de estas normas, la ausencia de individuación de un campo importante de deberes exigidos por la diligencia debida en el marco del principio de prevención, y la eventual consolidación por esta vía del principio precautorio y del principio de participación pública.

Palabras clave: Derecho consuetudinario, diligencia debida, principio de prevención, obligación de cooperación de buena fe, evaluación de impacto ambiental, interacciones. 


\section{ABSTRACT \\ ENVIRONMENTAL PROTECTION IN CUSTOMARY INTERNATIONAL LAW}

The article focuses on the current state of customary international law as regards environmental protection. Based on an analysis of the relevant case law, the article identifies a customary core consisting of the duty of due diligence as expressed through the prevention principle, and its procedural extensions through the obligation to cooperate in good faith, particularly by means of notification and consultation, and through the requirement to conduct a prior environmental impact assessment. Despite the fact that commentators have admitted the customary character of many other principles, the only principles effectively recognized in the case law as having an undisputed customary grounding are those addressed in this article. For this reason, the article does not merely select some principles but, rather, it focuses on those customary principles that have been effectively recognized as such. Subsequently, the article analyses each norm in detail as well as the interactions among them. It concludes with a brief reference to the current frontier of customary law in this area highlighting the difficulties arising from a sequential application of these norms, the need to further spell out the requirements of due diligence, and the potential consolidation through this avenue of the precautionary and public participation principles.

Keywords: customary law, due diligence, prevention principle, obligation to cooperate in good faith, environmental impact assessment, interactions. 